\title{
PERKEMBANGAN EMOSI KANAK-KANAK MENGGUNAKAN KAEDAH PENGAJARAN BERASASKAN AKTIVITI MUZIK
}

\section{The Emotional Development of Children by Using Art-based Music Activity}

\author{
Mohamad Albaree Abdul ${ }^{1}$, Hazhari Ismail ${ }^{2}$, Iylia Mohamad ${ }^{3}, \&$ Zaharah Osman $^{4}$ \\ Fakulti Pembangunan Manusia, Universiti Pendidikan Sultan Idris \\ Tanjung Malim, Perak, Malaysia ${ }^{1,2,3,4}$
}
albaree@fpm.upsi.edu.my ${ }^{1}$, hazhari@fpm.upsi.edu.my ${ }^{2}$,iylia@fpm.upsi.edu.my ${ }^{3}, \&$ zaharah@fpm.upsi.edu.my ${ }^{4}$

DOI: https://doi.org/10.37134/jpak.vol8.3.2019

Received: 09 October 2019; Accepted: 20 November 2019; Published: 23 December 2019

\begin{abstract}
ABSTRAK
Kanak-kanak sering berhadapan dengan masalah untuk mengurus dan mengawal emosi dengan baik. Isu ini kurang mendapat perhatian dalam kalangan orang dewasa yang menyebabkan kanak-kanak sering menunjukkan tingkah laku tidak terkawal, tekanan, dan kemurungan. Melalui pengajaran berasaskan aktiviti muzik, emosi kanak-kanak dapat dibentuk dengan baik. Oleh itu, kajian ini dijalankan untuk mengenal pasti perkembangan emosi kanak-kanak menggunakan kaedah pengajaran berasaskan aktiviti muzik di sebuah tadika di Puncak Alam, Selangor. Reka bentuk kajian ini adalah penyelidikan secara kualitatif yang berbentuk kajian kes. Sampel kajian melibatkan enam orang kanak-kanak yang terdiri daripada tiga orang kanak-kanak lelaki dan tiga orang kanakkanak perempuan yang berumur lima tahun, dan seorang guru tadika. Instrumen kajian ialah borang senarai semak untuk mengenal pasti perkembangan emosi kanak-kanak sebelum, semasa dan selepas pelaksanaan aktiviti pengajaran muzik, dan soalan temu bual untuk mendapatkan pandangan guru terhadap perkembangan emosi kanak-kanak menggunakan kaedah pengajaran berasaskan aktiviti muzik. Dapatan kajian menunjukkan pelaksanaan kaedah pengajaran berasaskan aktiviti muzik memberi impak yang positif dalam membantu perkembangan emosi kanak-kanak. Oleh itu, kaedah pengajaran berasaskan aktiviti muzik wajar digunakan oleh guru dalam proses pengajaran dan pembelajaran bagi membantu kanak-kanak mencapai perkembangan emosi yang memuaskan.
\end{abstract}

Kata kunci: perkembangan emosi, aktiviti muzik, kanak-kanak

\begin{abstract}
Children are always facing problems regarding how to manage and control their emotions effectively. This issue has not seemed as a headline for adults, which could cause the misbehavior, stress and depression of children. Through the learning process by using art-based music activity, children's emotions could be shaped better. Therefore, this research was aimed to identify the emotional development of children by using art-based music activity in the preschool at Puncak Alam, Selangor. The design of this study is qualitative research in the form of case studies. The sample of the study involved six 5 years old children where 3 girls and 3 boys, and a kindergarten teacher. The instrument of study is checklist form was used to see the emotional development of children in three different settings; pre, peri and post-teaching and learning of music activity, and interview session was held with a kindergarten teacher in order to gain their perception on this matter. Findings showed that art-based learning for music activity could have a positive impact to help the emotional development of children. Hence, art-based learning for music activity would be used by teachers in the teaching and learning process to help children achieve satisfactory emotional development.
\end{abstract}

Keyword: emotional development, music activity, children 


\section{PENGENALAN}

Perkembangan emosi kanak-kanak adalah sangat penting dalam kehidupan mereka. Ini kerana pembelajaran yang melibatkan emosi yang baik akan membantu proses pembelajaran dan pemudahcaraan $(\mathrm{PdPc})$ berjalan dengan lebih lancar dan sempurna. Perkembangan emosi boleh dipupuk sekiranya proses PdPc yang dilaksanakan oleh guru menarik dan menyeronokkan. Namun begitu, terdapat segelintir guru tidak melaksanakan pengajaran yang bersifatkan menarik dan menyeronokkan, malah lebih menekankan kepada proses PdPc yang berbentuk 'chalk and talk'. Menurut Rafiza (2017), pengajaran berbentuk 'chalk and talk' merupakan teknik yang amat membosankan dan menurunkan motivasi murid serta ilmu yang disampaikan tidak sepenuhnya diterima oleh murid.

Masalah tingkah laku, tekanan, kemurungan dalam kalangan kanak-kanak yang berlaku di tadika turut dikaitkan dengan kesan emosi mereka yang tidak stabil. Menurut Hamidah (2013), tingkah laku seseorang individu dikesan melalui emosi yang ditonjolkan. Masalah tingkah laku negatif ini berpunca daripada pembentukkan emosi negatif yang diperoleh daripada persekitaran mereka yang kurang memberangsangkan, seperti suasana pengajaran yang membosankan, masalah disiplin, dan masalah yang berlaku dalam keluarga. Kesannya, mewujudkan tingkah laku negatif seperti tidak menghormati guru, bergaduh dengan rakan, mengambil barang dari rakan tanpa pengetahuan, mengasingkan diri, dan tidak patuh arahan (Marziyeh Alivandi \& Khaidzir, 2017).

Perkembangan emosi merupakan salah satu komponen yang wajar dikembangkan dalam kehidupan kanak-kanak. Ini kerana perkembangan emosi dapat membantu mempengaruhi segala perbuatan, pandangan dan aktiviti kehidupan seharian kanak-kanak (Arba'ie, Nik Rafidah, Nurul Azimah, \& Intan Zahariah, 2014). Kanak-kanak yang mendapat didikan yang baik mampu menguruskan emosi dengan baik. Menurut Zaharah (2016), kebolehan mengurus emosi dengan baik dapat membantu mengembangkan kemahiran lain seperti kognitif, sosial, dan rohani. Kanak-kanak dapat menunjukkan emosi mereka seperti gembira, takut, sedih, marah dan benci berdasarkan keperluan yang memberi pengaruh besar sama ada positif mahupun negatif terhadap diri dan persekitaran mereka. Hal ini dipersetujui oleh Reinhard dan Lisa (2014) yang mendapati perkembangan emosi yang positif yang ditonjolkan oleh kanak-kanak memberi impak yang besar terhadap diri dan perbuatan mereka.

Perkembangan emosi kanak-kanak boleh dibina dan diperkembangkan berdasarkan kaedah pengajaran guru yang sesuai. Menurut Loy (2017), kaedah pengajaran guru memainkan peranan yang sangat penting dan memberi pengaruh besar terhadap perkembangan emosi kanak-kanak yang mampu membentuk perwatakkan imej kendiri mereka. Salah satu kaedah pengajaran yang digunakan oleh guru untuk merangsang perkembangan emosi kanak-kanak ialah pengajaran berasaskan aktiviti muzik. Ini kerana kaedah ini dianggap sesuai dengan persekitaran dan rutin harian kanak-kanak seperti menyanyi, menghasilkan bunyi-bunyian, bermain alat muzik dan menari (Azli, 2018). Tambahan pula, kanak-kanak dilihat suka memberi tindak balas yang positif, mendengar dan melibatkan diri apabila muzik dimainkan (Mawuse,2015). Oleh itu, kaedah pengajaran berasaskan aktiviti muzik mampu memberi kesan yang positif terhadap perkembangan emosi kanak-kanak. Pengalaman aktiviti muzik yang dirancang dengan baik sentiasa dianggap memberi makna, menyeronokkan serta memberi pengalaman secara langsung kepada kanak-kanak (Azli, 2013). 
Oleh itu, kajian ini dijalankan untuk mengenal pasti mengenal pasti perkembangan emosi kanak-kanak dengan menggunakan kaedah pengajaran berasaskan aktiviti muzik.

\section{METODOLOGI}

Kajian ini menggunakan pendekatan kualitatif yang berbentuk kajian. Pemilihan reka bentuk ini selaras dengan pandangan Clarke dan Creswell (2015) yang menyatakan pendekatan ini dapat melihat sesuatu isu dari pelbagai sudut yang berbeza. Kajian ini dijalankan di sebuah tadika di Puncak Alam, Selangor yang melibatkan enam orang sampel kanak-kanak berusia lima tahun yang terdiri daripada tiga orang kanak-kanak lelaki dan tiga orang kanak-kanak perempuan. Pemilihan sampel adalah melalui sampel bertujuan (purposeful sampeling) berdasarkan aspek tingkah laku yang berbeza sewaktu proses pengajaran berjalan di dalam bilik darjah seperti suka bersendirian, kurang bergaul dengan rakan sebaya dan mempunyai tingkah laku yang bermasalah, antaranya ialah tidak mendengar arahan guru, dan suka mengganggu rakan. Selain itu, kajian ini melibatkan seorang guru tadika untuk mengetahui pandangan guru tentang perkembangan emosi kanak-kanak melalui kaedah pengajaran berasaskan aktiviti muzik.

Pemilihan kaedah pengajaran berasaskan aktiviti muzik adalah berbentuk aktiviti nyanyian menggunakan lagu "Baby shark" seperti yang dicadangkan oleh guru. Perincian pelaksanaan kaedah pengajaran berasaskan aktiviti muzik dari aspek hari, masa, lagu, dan jenis aktiviti ditunjukkan dalam Jadual 1 berikut;

Jadual 1

Pelaksanaan Kaedah Pengajaran berasaskan Aktiviti Muzik

\begin{tabular}{lcl}
\hline \multicolumn{1}{c}{ Hari / Masa } & \multicolumn{1}{c}{ Lagu } & \multicolumn{1}{c}{ Jenis Aktiviti } \\
\hline $\begin{array}{l}\text { Isnin } \\
10.00 \mathrm{am}-10.30 \mathrm{am}\end{array}$ & Baby Shark & Nyanyian dan tayangan video lagu Baby Shark. \\
$\begin{array}{l}\text { Rabu } \\
11.30 \mathrm{am}-12.00 \mathrm{pm}\end{array}$ & Baby Shark & $\begin{array}{l}\text { Nyanyian, tayangan video lagu Baby Shark } \\
\text { dan membuat pergerakan. }\end{array}$ \\
$\begin{array}{l}\text { Khamis } \\
08.00 \mathrm{am}-08.40 \mathrm{am}\end{array}$ & Baby Shark & $\begin{array}{l}\text { Nyanyian, tayangan video lagu Baby Shark, } \\
\text { membuat pergerakan dan lakonan. }\end{array}$ \\
\hline
\end{tabular}

Pengkaji mengguakan kaedah pemerhatian, dan kaedah temu bual untuk mengumpul data. Instrumen kajian ialah borang senarai semak yang mengandungi 13 item soalan yang diadaptasi daripada Zaharah (2016) untuk mengenal pasti perkembangan emosi kanak-kanak sebelum, semasa dan selepas pelaksanaan aktiviti pengajaran muzik, dan soalan temu bual untuk mendapatkan pandangan guru terhadap perkembangan emosi kanak-kanak menggunakan kaedah pengajaran berasaskan aktiviti muzik.

\section{DAPATAN KAJIAN}

Dapatan kajian menunjukkan kaedah pengajaran berasaskan aktiviti muzik memberi pengaruh yang sangat positif terhadap perkembangan emosi kanak-kanak. Hasil analisis berdasarkan pemerhatian menggunakan borang senarai semak, perkembangan emosi kanak-kanak sebelum, semasa, dan selepas dilihat mempunyai perubahan ke arah yang baik dan memuaskan.

Melalui analisis item, pengkaji mendapati perkembangan emosi kanak-kanak sebelum, semasa, dan selepas dengan menggunakan kaedah aktiviti muzik mengalami perubahan yang 
sangat ketara. Ini dapat dijelaskan melalui item 3 iaitu "Menunjukkan kegembiraan melakukan aktiviti" yang dirangka bertujuan untuk mengenal pasti sama ada kanak-kanak menunjukkan emosi yang gembira apabila melakukan sesuatu aktiviti ataupun sebaliknya. Dapatan menunjukkan sebelum menggunakan kaedah pengajaran aktiviti muzik, keenam-enam sampel dilihat mempamerkan tingkah laku dan emosi yang bersifat negatif dan menunjukkan "Tidak" terhadap item ini. Namun begitu, setelah guru memasangkan video lagu "Baby Shark" dan menjalankan aktiviti, keenam-enam sampel dilihat mempamerkan emosi yang gembira dan melibatkan diri secara aktif semasa aktiviti dijalankan. Tambahan pula, selepas aktiviti pengajaran berlangsung didapati keenam-enam sampel masih menunjukkan ekspresi emosi gembira dan saling berinteraksi dengan rakan-rakan di dalam kelas.

Kanak-kanak juga berjaya menguasai item 4 "Menunjukkan ekspresi seperti suka, yakin, mesra dan ketawa". Pada peringkat permulaan pengajaran, keenam-enam sampel tidak berminat terhadap proses pengajaran guru. Ini kerana pengkaji mendapati keenam-enam sampel menunjukkan tingkah laku dan emosi yang kurang menyenangkan seperti menggangu rakan sebaya, menangis, suka bersendirian, dan tidak mendengar arahan yang diberikan oleh guru. Namun begitu, apabila lagu "Baby Shark" dimainkan, pengkaji melihat keenam-enam sampel menunjukkan perubahan seperti menumpukan perhatian, menari dan menyanyi lagu tersebut dengan rasa gembira dan yakin. Di samping itu, pengkaji mendapati pelaksanaan aktiviti muzik memberi kesan terhadap tahap keyakinan dan keinginan untuk belajar. Ini dapat dilihat apabila keenam-enam sampel membuat pergerakan bebas semasa lagu dimainkan, mereka mempamerkan tahap keyakinan yang tinggi sehingga meminta guru untuk memasangkan lagu "Baby Shark" berulang kali selepas tamat aktiviti tersebut.

Penggunakan kaedah pengajaran berasaskan aktiviti muzik sememangnya memberi kesan positif terhadap perkembangan emosi kanak-kanak. Dapatan menunjukkan sebelum pelaksanaan aktiviti muzik, empat orang sampel menunjukkan "Ya" pada item 9 iaitu "Cepat marah dan mengamuk", item 10 "Sedih atau suka menangis", dan item 12 "Terasa takut, cemas dan malu". Berdasarkan pemerhatian, keempat-empat sampel mempamerkan emosi yang kurang menarik sewaktu proses pengajaran dan pembelajaran kerana sampel tidak mampu mengurus emosi mereka dengan baik dan proses pengajaran guru yang kurang mendapat perhatian dan sambutan daripada mereka. Namun begitu, apabila guru memasang lagu "Baby Shark", keempat-emapt sampel tersebut kelihatan mengalami perubahan emosi yang sangat memberangsangkan seperti menyanyi dengan penuh yakin dan gembira, menari, dan mendekati guru tersebut.

Perubahan perkembangan emosi turut dilihat selepas proses pengajaran berasaskan aktiviti muzik, apabila keenam-enam sampel tidak lagi menunjukkan emosi yang bersifat negatif, malah sering menunjukkan emosi positif seperti gembira, suka, dan tertawa. Ringkasan dapatan kajian ini ditunjukkan dalam Jadual 2 berikut;

Jadual 2

Perkembangan Emosi Kanak-kanak Sebelum, Semasa, dan Selepas Menggunakan Kaedah Pengajaran Berasaskan Aktiviti Muzik

\begin{tabular}{llcccccc}
\hline & \multirow{2}{*}{ Item } & \multicolumn{2}{c}{ Sebelum } & \multicolumn{2}{c}{ Semasa } & \multicolumn{2}{c}{ Selepas } \\
\cline { 3 - 7 } No. & Ya & Tidak & Ya & Tidak & Ya & Tidak \\
\hline 1. & $\begin{array}{l}\text { Memberi perhatian dan mendengar } \\
\text { arahan guru. }\end{array}$ & 1 & 5 & 6 & 0 & 6 & 0
\end{tabular}


2. Menyanyi dengan penuh semangat sambil membuat pergerakan.

3. Menunjukkan

4. Menunjukkan ekspresi seperti suka, yakin, mesra dan ketawa.

5. Cuba menonjolkan diri untuk menarik perhatian orang dipersekitarannya.

6. Gelisah, selalu bergerak ke sana ke sini.

7. Kurang menumpukan perhatian terhadap aktiviti.

8. Mengganggu rakan sebaya dan suka berkelahi.

9. Cepat marah dan mengamuk.

10. Sedih/ suka menangis.

11. Bersendirian dan tidak bergaul dengan rakan sebaya.

12. Terasa takut, cemas dan malu.

13. Suka menjerit-jerit dan cemburu dengan kanak-kanak yang lain.

$\begin{array}{llllll}0 & 6 & 4 & 2 & 6 & 0 \\ 0 & 6 & 6 & 0 & 6 & 0 \\ 0 & 6 & 6 & 0 & 6 & 0 \\ 3 & 3 & 4 & 2 & 6 & 0 \\ & & & & & \\ 6 & 0 & 5 & 1 & 0 & 6 \\ 6 & 0 & 0 & 6 & 0 & 6 \\ 3 & 3 & 3 & 3 & 0 & 6 \\ 4 & 2 & 3 & 3 & 0 & 6 \\ 4 & 2 & 1 & 5 & 0 & 6 \\ 3 & 3 & 0 & 6 & 0 & 6 \\ 4 & 2 & 1 & 5 & 0 & 6 \\ 3 & 3 & 1 & 5 & 0 & 6\end{array}$

Bagi mengukuhkan dapatan kajian ini, temu bual turut dijalankan terhadap seorang guru untuk mengetahui pandangannya terhadap perkembangan emosi kanak-kanak menggunakan kaedah pengajaran berasaskan aktiviti muzik. Pengkaji mendapati penggunaan kaedah pengajaran berasaskan aktiviti muzik sememangnya sesuai untuk perkembangan emosi kanak-kanak. Ini berdasarkan perakuan dan pandangan guru;

"...Sebelum ini saya mengajar menggunakan kaedah tradisional, saya lihat kanakkanak tidak minat untuk belajar, bila saya cuba kaedah ini saya lihat kanak-kanak yang sedih dan kuat marah terus berubah menjadi ceria, seronok dan gembira, sehinggakan mereka nak saya pasang lagu ini lagi...". (Guru Tadika 1, T1)

Guru juga menjelaskan penggunakan kaedah aktiviti muzik mampu mempengaruhi tingkah laku dan tindakan kanak-kanak;

"...Saya rasa kagum lah guna kaedah ini, sebab kanak-kanak yang problem memberi tumpuan yang sepenuhnya, lebih-lebih lagi lagu ini dekat dengan mereka, saya tengok tingkah laku mereka pun semakin baik...". (Guru Tadika 1, T2)

Di samping itu, guru menjelaskan kaedah pengajaran berasaskan aktiviti muzik mampu mengeratkan hubungan antara guru dengan murid, dan murid dengan murid. Ini dijelaskan berdasarkan kenyataan yang diberikan oleh guru;

"...Awak nak tahu, bila saya gunakan kaedah ini, saya tengok kanak-kanak lebih minat untuk belajar, lebih-lebih lagi kanak-kanak yang problem. Bukan itu sahaja, malah pergaulan mereka antara saya dan murid lain sangat bagus. Mereka dah mula rapat dengan saya dan murid-murid lain..." (Guru Tadika 1, T3). 
Berdasarkan kenyataan yang diberikan oleh guru, pengkaji mendapati penggunaan kaedah pengajaran berasaskan aktiviti muzik bukan sahaja membantu kanak-kanak dari aspek perkembangan emosi, malah ianya mampu membentuk perkembangan dan kemahiran yang ada pada diri kanak-kanak.

\section{PERBINCANGAN}

Dapatan kajian menunjukkan penggunaan kaedah pengajaran berasaskan aktiviti muzik memberi pengaruh besar terhadap perkembangan emosi kanak-kanak. Ini kerana pelaksanaan aktiviti muzik membolehkan kanak-kanak mampu mengurus dan meluahkan emosi mereka dengan cara yang betul (Zaharah, 2016). Berdasarkan dapatan kajian, keenam-enam sampel menunjukkan perkembangan emosi yang sangat memuaskan setelah penggunaan lagu "Baby Shark" yang berteraskan kepada empat jenis aktiviti seperti aktiviti nyanyian, tayangan video lagu, pergerakan, dan lakonan yang dilaksanakan oleh guru. Ini menunjukkan aktiviti muzik mampu menarik perhatian dan minat kanak-kanak untuk belajar (Fulvia, 2015). Dapatan ini disokong oleh Reney (2017) yang menyatakan teknik nyanyian berunsurkan aktiviti muzik yang dilaksanakan di dalam kelas mampu meningkatkan kefahaman murid tentang subjek yang dipelajari. Tambahan pula, kemahiran-kemahiran lain seperti kemahiran komunikasi, tahap keyakinan diri, sifat kerjasama dan hubungan bersosial dapat diperkembangkan melalui pelaksanaan aktiviti muzik (Md Jais, 2017). Ini dipersetujuhi oleh Siti Norhidayah dan Roziah Sidik (2017) yang menjelaskan pengajaran muzik merupakan salah satu pendekatan terapi yang turut digunakan dalam tamadun Islam bagi membantu perkembangan emosi, psikomotor, sosial, dan kognitif seseorang.

Perkembangan emosi kanak-kanak perlu diberi perhatian sewajarnya kerana kanakkanak yang mempunyai masalah dalam mengurus emosi mereka akan menghadapi masalah dari aspek tingkah laku, pergaulan dengan rakan sebaya, komunikasi dan kurang keyakinan diri (Azadeh, 2015). Ini selaras dengan Maguire, Niens, MccCannc dan Connolly (2016), yang berpendapat tingkah laku bermasalah kanak-kanak yang sering berlaku di dalam bilik darjah dan menyebabkan gangguan dalam proses pengajaran guru adalah disebabkan kanak-kanak tidak mampu mengurus emosi mereka dengan baik. Oleh itu, langkah segera perlu diambil oleh pendidik dengan mempelbagaikan dan menggunakan kaedah pengajaran yang menyeronokkan seperti aktiviti muzik agar emosi kanak-kanak dapat diperkembangkan dengan cara yang lebih baik. Ini kerana kaedah pengajaran berasaskan aktiviti muzik sememangnya merupakan kaedah yang sewajarnya digunakan oleh guru untuk membantu perkembangan emosi kanak-kanak.

\section{KESIMPULAN}

Kaedah pengajaran berasaskan aktiviti muzik memberi kesan yang positif terhadap perkembangan emosi kanak-kanak. Ini kerana aktiviti muzik merupakan kaedah yang menyeronokkan dan sesuai digunakan bagi menarik minat kanak-kanak untuk belajar. Oleh itu, guru memainkan peranan yang sangat penting bagi mempelbagaikan lagi kaedah pengajaran berasaskan aktiviti muzik supaya dapat mengatasi kanak-kanak yang mempunyai masalah dalam pengurusan emosi. Seterusnya, dapat membantu kanak-kanak mencapai tahap perkembangan emosi yang optimum pada masa akan datang. 


\section{RUJUKAN}

Arba'ie Sujud, Nik Rafidah Nik Muhamad Affendi, Nurul Azimah Abdull Sedik, \& Intan Zahariah Gaisun. (2014). Ekspresi emosi melalui bahan bacaan sastera kanak-kanak. Jurnal Melayu, 13(1), $72-84$.

Azadeh, O. P. (2015). Children's perception of emotion in music: a cross-cultural study. Tesis Sarjana Music, Mind and Technology, University Jyväskylä.

Azli Ariffin. (2013). Pembinaan modul pedagogi MK2K berasaskan muzik untuk kurikulum prasekolah. Tesis Sarjana Pendidikan Awal Kanak-Kanak, Universiti Pendidikan Sultan Idris Kampus Sultan Azlan Shah, Tanjong Malim, Perak.

Azli Ariffin. (2018). Reka bentuk model aktiviti penggunaan lagu kanak-kanak Melayu tradisional untuk peningkatan imaginasi kreatif prasekolah. $\mathrm{PhD}$ thesis, University of Malaya.

Clark, 1., P., \& Creswell, J., W. (2015). Understanding research. New Jersey: Pearson Education.

Fulvia, A., C. (2015). Emotional effects of music therapy on children wih special needs. Journal Plus Education, 12(1), 178-183.

Hamidah Sulaiman. (2013). Kecerdasan emosi menurut Al-Quran dan al-sunnah: Aplikasinya dalam membentuk akhlak remaja. O-JIE: Online Journal of Islamic Education, 1(2). 51-57.

Loy, C. L. (2017). Boneka sebagai alat pedagogi dalam perkembangan sosial dan emosi kanak-kanak prasekolah. Jurnal Pendidikan Awal Kanak-kanak Kebangsaan, 6, 45-56.

Maguire, L. K., Niens, U., MccCannc, M. \& Connolly, P. (2016). Emotional development among early schoolage children: Gender differences in the role of problem behaviours. Educational psychology, 36(8), 1408-1428.

Marziyeh Alivandi Vafa \& Khaidzir Ismail. (2017). Filial therapy work best for preschooler's children with challenging behavior. e-bangi, 3(3). 1-13.

Mawuse, A. (2015). Folk song in early childhood music education: A study in some selected schools in AfadjatoSouth District. Unpublished Phd's Thesis. University Of Education, Winabe.

Md. Jais. (2017). The effectiveness of dalcroze music approach in enhancing musical coordination skill among year 4 students in urban area. Malaysian Journal of Social Sciences and Humanities (MJSSH), 2(1), 5465.

Rafiza Abdul Razak. (2017). Strategi pembelajaran aktif secara kolaboratif atas talian dalam analisis novel Bahasa Melayu. JuKu: Jurnal Kurikulum \& Pengajaran Asia Pasifik, 1(3), 34-46

Reinhard, P., \& Lisa, L. G. (2014). International handbook of emotions in education. New york and london: Routledge Taylor and Francis Group.

Reney Pantun. (2017). Penggunaan teknik nyanyian dalam meningkatkan kefahaman murid tahun dua dalam topik pembundaran. Proceedings of the ICECRS, 1(1), 677-686.

Siti Norhidayah Mohd Sufie \& Roziah Sidik. (2017). What is medical music therapy in Islamic civilization? International Journal of Business and Social Science, 8(3).

Zaharah Osman. (2016). Perkembangan emosi kanak-kanak menggunakan lagu Didi \& Friends. Jurnal Pendidikan Awal Kanak-kanak Kebangsaan, 5, 49-60. 